\title{
MANEJ O DO NITROGÊNIO NO MILHO EM SUCESSÃO A PLANTAS DE COBERTURA DE SOLO, SOB PLANTIO DIRETO(1)
}

\author{
C. J . BASSO(2) \& C. A. CERETTA ${ }^{(3)}$
}

\begin{abstract}
RESUMO
Estabelecida a hipótese de que a antecipação da adubação nitrogenada promove acréscimo no rendi mento de grãos de milho pela maior disponi bi lidade de $\mathbf{N}$ nos estádios iniciais de desenvolvimento, foi realizado um trabalho com o objetivo de avaliar diferentes manejos de $\mathbf{N}$ para o milho cultivado em sucessão a plantas de cobertura de solo. $O$ experimento foi desenvolvido em área do Departamento de Solos da Universidade Federal de Santa Maria (RS), nos anos agrícolas de 1996/97, 1997/98 e 1998/99, em Argissolo Vermel ho distrófico arênico (Hapludalf). 0 delineamento experimental foi de blocos ao acaso com parcelas subdivididas e três repetições. Nas parcelas principais ( $25 \times 5 \mathrm{~m}$ ), foram cultivadas três espécies para cobertura de solo no inverno: aveia preta (Avena strigosa Schieb), aveia preta + ervilhaca (Vicia sativa L.) e nabo forrageiro (Raphanus sativus). Nas subparcelas $(5 \times 5 \mathrm{~m})$, aplicou-se $\mathrm{N}$ para o milho da seguinte manei ra: (a) 00-00-00, (b) 00-30-90, (c) 30-30-60, (d) 60-30-30 e (e) 90-30-00, cuja seqüência para cada tratamento corresponde à quantidade de $\mathbf{N}$ em $\mathbf{~ k g ~ h a}^{-1}$ aplicado em pré-semeadura-semeadura-cobertura do milho. A aplicação de $\mathbf{N}$ em pré-semeadura foi realizada após o manejo das plantas de cobertura de solo no inverno, enquanto em cobertura o $\mathbf{N}$ foi aplicado quando as plantas de milho estavam com quatro a seis fol has desenroladas. Utilizou-se uréia como fonte de N. Segundo os resultados, o mil ho cultivado em sucessão ao consórcio com aveia preta + ervilhaca mostrou melhor desempenho do que quando cultivado sobre resíduos de aveia preta e nabo forrageiro. A aplicação de $\mathbf{N}$ em pré-semeadura do milho é uma atitude de risco, sendo mais segura a aplicação de $\mathbf{N}$ na semeadura e em cobertura.
\end{abstract}

Termos de indexação: adubação nitrogenada, épocas de aplicação, sucessão de culturas.

\footnotetext{
(1) Parte da Tese de Mestrado do primeiro autor, apresentada ao Programa de Pós-graduação em Agronomia, Universidade F ederal de Santa Maria - UFSM. Recebido para publicação em setembro de 1999 e aprovado em junho 2000.

(2) Engenheiro-Agrônomo, MSc., Doutorando do Programa de Pós-Graduação em Agronomia, Universidade Federal de Santa Maria - UFSM. CEP 97105-900 Santa Maria (RS)

(3) Engenheiro-Agrônomo, Dr., Professor Titular do Departamento de Solos, Universidade Federal de Santa Maria, Santa Maria, RS. CEP: 97105-900. Bolsista do CNPq. e-mail: ceretta@ccr.ufsm.br
} 


\title{
SUMMARY: NITROGEN FERTILIZATION MANAGEMENT FOR CORN GROWN AFTER WINTER COVER CROPS UNDER NO- TILLAGE
}

\begin{abstract}
Based on the hypothesis that antecipating of nitrogen application can increase corn grain yield dueto moreN availability in theinitial stages of devel opment, fiel d studies were conducted for threagricultural years (1996/97, 1997/ 98, and 1998/99) to evaluatedifferent types of management of $\mathrm{N}$ application for corn cultivated after winter soil cover crops. This work was developed on a Hapludalf soil, at the experimental area of the Soil Science Departament at theF ederal U niversity of Santa Maria (RS, Brazil). A compl eterandomized block design with split-pl ots and three replications was used. In the main plots ( $25 \times 5 \mathrm{~m}$ ), threewinter soil cover crops weretested: (a) black oats (Avena strigosa Schieb); (b) a mixture of oats + common vetch (Vicia sativa L.), and (c) oi Iseed radish (Raphanus sativus). In the sub plots $(5 \times 5 \mathrm{~m})$, the amount of $\mathrm{N}\left(\mathrm{kg} \mathrm{ha}^{-1}\right)$ was applied as broadcast beforecorn sowing, at corn sowing, and as side-dressing, respectively: (a) 00-00-00, (b) 00-30-90, (c) 30-30-60, (d) 60-30-30, and (d) 90-30-00. N application before corn sowing was done after the dessication of the cover crops, while as topdressing, $\mathrm{N}$ was applied when the corn plants presented 4 to 6 uncoiled leaves. U rea was used as a source of $N$. Theresults showed that the corn cultivated after oats + common vetch had better performance than when cultivated after black oats and oil seed radish. Nitrogen application beforecorn sowing is a risky practice, while $\mathrm{N}$ application at sowing and as topdressing is a safe recommendation.
\end{abstract}

Index terms: nitrogen fertilization, timing of application, crops systems.

\section{NTRODUÇÃO}

O sucesso do sistema plantio direto depende da adoção de sistemas de culturas que privilegiem a produção e manutenção de resíduos culturais na superfície do solo. Com isso, pode-se el evar oteor de matéria orgânica do solo, que depende fundamentalmente da quantidade de matéria seca produzida pelos sistemas de culturas (Gonçalves \& Ceretta, 1999), e propiciar alterações nos sistemas tradicionais de manejo de fertilizantes nitrogenados.

No sistema plantio direto, tem havido maior preocupação em elevar a disponibilidade de $\mathrm{N}$ no início do crescimento do milho, por ser ele, na mai oria dos sistemas de produção, cultivado em sucessão a gramíneas. Isto pode significar comprometimento da quantidade de $\mathrm{N}$ disponível para o milho, pois, segundo Salet et al. (1997), a imobilização de N mineral pela biomassa microbiana é a principal causa da menor disponibilidadede N. Por isso, Bayer (1993) ressalta que a adubação nitrogenada no sistema plantio direto é feita de forma idêntica àquela do sistema tradicional com revolvimento de solo, aplicando-se de 20 a $30 \%$ a mais de $\mathrm{N}$ na semeadura no sistema plantio direto.

A utilização de leguminosas antecedendo o milho normal mente resulta em menor imobilização de N. Por essa razão, Ritchie et al. (1993) enfatizam que, apesar de serem pequenas as exigências nutricionais do milho nos estádios iniciais de desenvolvimento, altas concentrações de nutrientes na zona radicular são benéficas, pois promovem bom arranqueinicial. Essa foi uma das justificativas dadas por Yamada (1996), quando obteve mai or produção de milho com aplicação de $30-50 \mathrm{~kg} \mathrm{ha}^{-1}$ de $\mathrm{N}$ na semeadura, comparado com o manejo tradicional de $\mathrm{N}$ (semeadura + cobertura), utilizando de $10-15 \mathrm{~kg} \mathrm{ha}^{-1}$ de $\mathrm{N}$ na semeadura do milho.

As características do sistema plantio direto fazem com que as principais al terações quanto à adubação nitrogenada para o mil ho sejam relacionadas com a época de aplicação (Ceretta \& Fries, 1998). Ceretta (1998) apresenta as vantagens operacionais da aplicação de $\mathrm{N}$ em pré-semeadura do milho cultivado em sucessão à aveia preta. I sso, somado ao desconhecimento da fisiologia da planta de milho, faz com que, em muitas situações de lavoura, a aplicação de $\mathrm{N}$ em cobertura no mil ho seja feita após a definição da produção potencial, que ocorre quando a planta está com quatro folhas, ou seja, com aproximadamente duas semanas da emergência, conforme ilustram Fancelli \& Dourado Neto (1996).

Nosolo, o nitrato podeser lixiviado, porque, além de muito solúvel, mostra baixa energia de adsorção às partículas do solo, podendo tal fato comprometer o sincronismo entre oN mineral disponível nosoloe a cinética de absorção pelas plantas.

Estabeleceu-se a hipótese de que aplicações antecipadas de $\mathrm{N}$ para o milho favorecem a produtividade de grãos. Portanto, estetrabalho teve 
por objetivo avaliar diferentes manejos de $\mathrm{N}$ para o milho cultivado em sucessão a plantas de cobertura de solo no sistema plantio direto.

\section{MATE RIAL E MÉTODOS}

O trabal ho foi realizado em campo, nos anos agrícolas de 1996/97, 1997/98 e 1998/99 sob osistema plantio direto, em área do Departamento de Solos da Universidade F ederal deSanta Maria (RS). O sol o é classificado como Argissolo Vermelho distrófico arênico (Hapludalf) (EMBRAPA, 1999), textura superficial franco-arenosa no horizonte $A$ e francoargilosa no $B$. Nos dois anos que antecederam a instalação do experimento, toda a área experimental foi cultivada com aveia preta no inverno e soja no verão, no sistema plantio direto.

O solo amostrado no início do experimento e na profundidade de $0-10 \mathrm{~cm}$ apresentou as seguintes características: teor de argila $110 \mathrm{~g} \mathrm{~kg}^{-1}$; $\mathrm{pH}$ em H $\mathrm{H}_{2} \mathrm{O}$ (1:1) 5,5; índiceSMP 6,1; P 13 mg dm 3 ; $K 58 \mathrm{mg} \mathrm{dm}^{-3}$; M.O. $19 \mathrm{~g} \mathrm{~kg}^{-1}$ de solo; $\mathrm{Ca}^{2+}+\mathrm{Mg}^{2+} 4,7 \mathrm{cmol}_{\mathrm{C}} \mathrm{dm}^{-3}$; e $\mathrm{Al}^{3+} 0,0$. Maiores detalhes sobre a textura do solo foram determinados por Matias (1996) na camada de 0-40 cm, o qual encontrou teores de 550, 280 e $160 \mathrm{~g} \mathrm{~kg}^{-1}$ para as frações areia total, silte e argila, respectivamente. Os resultados da análise de solo foram obtidos no laboratório de rotina do Departamento deSolos da UFSM, seguindo o método descrito em Tedesco et al. (1995), sendo utilizado o extrator de Mehlich para análise de $\mathrm{P}$. O solo foi amostrado na camada de 0-10 cm, porque vários trabal hos têm demonstrado boa correlação entre a avaliação da fertilidade do solo nessa camada e a resposta das culturas, conforme apresenta Bartz (1998).

O delineamento experimental foi o de blocos casualizados com parcelas subdivididas e três repetições. Nas parcelas principais de $25 \times 5 \mathrm{~m}$, foram plantadas as seguintes espécies para cobertura de solo no inverno: aveia preta (Avena strigosa Schieb), aveia preta+ervilhaca (Vicia sativa L.) e nabo forrageiro (Raphanus sativus). Nas subparcelas de $5 \times 5 \mathrm{~m}$, foram testados os seguintes manejos de N à cultura do milho: (a) 00-00-00; (b) 00-30-90; (c) 30-30-60; (d) 60-30-30 e (e) 90-30-00, cuja seqüência para cada tratamento correspondeà quantidade de $\mathrm{N}$ em $\mathrm{kg} \mathrm{ha}^{-1}$ aplicado em présemeadura-semeadura-cobertura do milho. A aplicação de $\mathrm{N}$ em pré-semeadura foi realizada após o manejo das plantas de cobertura desolo no inverno, enquanto em cobertura o $\mathrm{N}$ foi aplicado quando as plantas de milho estavam com quatro a seis fol has desenroladas. Utilizou-se uréia como fonte de N .

$\mathrm{Na}$ semeadura das plantas de cobertura de solo no inverno, foram utilizados 100,80 e $15 \mathrm{~kg} \mathrm{ha}^{-1} \mathrm{de}$ semente deaveia preta, ervilhaca e nabo forrageiro, respectivamente. $\mathrm{Na}$ consorciação aveia preta + ervilhaca, foi utilizada uma proporção de 30 e $70 \%$ da densidade de semeadura, ou seja, 30 e $56 \mathrm{~kg} \mathrm{ha}^{-1}$ de sementes de aveia preta e ervilhaca, respectivamente.

No primeiroano, nas plantas de cobertura de solo no inverno, foram aplicados $200 \mathrm{~kg} \mathrm{ha}^{-1}$ de adubo mineral da fórmula 5-20-20 e, no segundo e terceiro ano, $40 \mathrm{~kg} \mathrm{ha}^{-1} \mathrm{de}_{2} \mathrm{O}_{5}$ eK $\mathrm{K}_{2} \mathrm{O}$, utilizando superfosfato tripl o e cl or eto de potássio, respectivamente, e mais $10 \mathrm{~kg} \mathrm{ha}^{-1}$ de $\mathrm{N}$ na forma de uréia. A semeadura das plantas de cobertura e a aplicação de fertilizantes foram feitas a lanço sobre os resíduos vegetais, passando-se, posteriormente, uma grade leve esem trava para melhorar o contato das sementes com o solo.

O manejo das plantas de cobertura de solo no inverno consistiu da aplicação do herbicida Roundup na dose $3 \mathrm{~L} \mathrm{ha}{ }^{-1} \mathrm{e}$, posteriormente, passou-se o rolo faca. Para melhor interpretar os resultados, no primeiro parágrafo de resultados e discussão, são apresentadas as produções de massa de matéria seca das espécies de cobertura de solo, determinadas por Basso (1999), que coletou duas subamostras de $0,25 \mathrm{~m}^{2}$ por parcela, as quais, após atingirem peso constanteem estufas, foram pesadas, não retornando para as parcelas no campo.

A semeadura do milho foi feita diretamente sobre os restos culturais das plantas de cobertura de solo aos 27, 23 e 17 dias da aplicação do N em présemeadura no primeiro, segundo e terceiro ano, respectivamente. Para isso, utilizou-se semeadora tratorizada com espaçamento de um metro entrel inhas euma distribuição de sete sementes por metrolinear, desbastando-se, posteriormente, para 5,5 plantas por metro linear, perfazendo uma

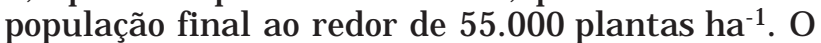
milho utilizado foi o híbrido Braskalb XL-212, considerado de ciclo precoce. Deficiências hídricas durante o cultivo do milho foram contornadas por meio de irrigação por aspersão, tomando-se, como referencial, o aspecto das plantas e a umidade do solo.

A adubação com fósforo e potássio para o milho foi feita a lanço, após o manejo das plantas de cobertura, na dose de $100 \mathrm{~kg} \mathrm{ha}^{-1}$ de $\mathrm{P}_{2} \mathrm{O}_{5}$ e K ${ }_{2} \mathrm{O}$, utilizando-se, como fontes, o superfosfato tripl o e o cloreto de potássio, respectivamente, sendo as quantidades aplicadas com base na recomendação da Comissão de Fertilidade do Solo - RS/SC (1995). A aplicação de N (uréia) em pré-semeadura do milho foi feita a lanço, enquanto na semeadura aplicou-se em um pequeno sulco ao lado da linha de semeadura com aproximadamente $5 \mathrm{~cm}$ de profundidade. $\mathrm{Em}$ cobertura, a aplicação do $\mathrm{N}$ foi feita superficialmente cerca de $20 \mathrm{~cm}$ ao lado da linha do milho.

No estádio de pleno florescimento do milho, coletaram-se aleatoriamente, dentro de cada subparcela, cinco plantas de milho para avaliação 
da massa da matéria seca, que foi determinada secando-se as plantas em estufa a $65^{\circ} \mathrm{C}$ até peso constante. $\mathrm{O}$ teor de $\mathrm{N}$ no tecido da parte aérea do milho foi obtido digerindo-se 0,2 $\mathrm{g}$ de matéria seca, com $\mathrm{H}_{2} \mathrm{SO}_{4}$ e mistura de digestão $\left(\mathrm{Na}_{2} \mathrm{SO}_{4}\right.$, $\mathrm{CuSO}_{4} .5 \mathrm{H}_{2} \mathrm{O}$ e selênio) seguida de destilação de arraste de vapor semimicro Kjeldahl, segundo Tedesco et al. (1995).

A produtividade de grãos de milho foi avaliada col hendo-se manual menteas quatrolinhas centrais de cada subparcela, descartando-se 0,5 m de cada extremidade, perfazendo uma área total de $16 \mathrm{~m}^{2}$, tendo-se corrigido o peso de grãos para $13 \%$ de umidade.

No primeiro ano agrícola (1996/97), foram feitas amostragens desolo para a determinação do teor de $\mathrm{N}$ mineral, nas profundidades de 0-5, 5-10, 10-20 e 20-40 cm, nas seguintes épocas: (1) antes da aplicação do N em pré-semeadura do milho; (2) imediatamente antes da semeadura do milho; (3) imediatamenteantes da apl icação do $\mathrm{N}$ em cobertura no milhoe (4) no pleno florescimento do milho. Como a aplicação do N em pré-semeadura foi feita a lanço, a amostragem de solo imediatamente antes da semeadura do milho foi feita em toda a área de cada subparcela e com trado calador (cinco subamostragens), enquanto as demais amostragens foram feitas com duas subamostragens, abrindo-se um sulco transversal à linha de milho com $1 \mathrm{~m}$ de comprimento, aproximadamente $12 \mathrm{~cm}$ de largura e $20 \mathrm{~cm}$ de profundidade. Nestes sulcos, col etavamse as amostras estratificadas até $20 \mathrm{~cm}$ em toda a seção, enquanto, para a amostra de $20-40 \mathrm{~cm}$, utilizava-se trado holandês com tradagens ao longo de toda a seção.

No segundo ano agrícola (1997/98), em razão de fortes chuvas ocorridas no período da aplicação do $\mathrm{N}$ em pré-semeadura até à semeadura do milho, optou-se por fazer somente uma aval iação dos teores de $\mathrm{N}$ mineral no período imediatamente anterior à semeadura do milho, para obter um valor comparativo com os resultados encontrados nesse mesmo período no ano anterior, mas apenas no sistema aveia preta/milho, porque este é o sistema de sucessão mais utilizado pel os produtores.

No terceiro ano agrícola (1998/99), não foi avaliado o teor de $\mathrm{N}$ mineral no solo. As determinações de $\mathrm{N}$ mineral nosol o foram realizadas por meio de arraste de vapor semimicro Kjeldahl, segundo Tedesco et al. (1995), sendo o N-mineral extraído por solução de $\mathrm{KCl} 1 \mathrm{~mol} \mathrm{~L} \mathrm{~L}^{-1}$. Uma alíquota de $20 \mathrm{~mL}$ da solução extraída com $\mathrm{KCl}$ foi usada para a determinação do N-mineral. Numa primeira destilação, foi adicionado $\mathrm{MgO}$ para determinação de $\mathrm{NH}_{4}{ }^{+}$e, posteriormente, numa segunda destilação da mesma amostra, foi adicionada liga Devarda à determinação de $\mathrm{NO}_{3}{ }^{-}$.

A análise estatística dos dados constou da análise de variância, com aplicação do teste $F$, usando-se o pacote estatístico SAS, tendo-se considerado a análise estatística ea variável teor de N mineral no solo em diferentes profundidades como subsubparcelas. Utilizou-se o teste de Duncan a 5\% para a comparação de médias.

\section{RESULTADOS E DISCUSSÃO}

\section{N mineral do solo}

As produções de matéria seca de aveia preta, aveia preta +ervilhaca e nabo forrageiro foram, respectivamente, de 7,36, 6,11, 5,16 $\mathrm{Mg} \mathrm{ha}^{-1}$, em 1996, reduzindo, em 1997, para 4,05, 4,61, 3,40 M g ha-1 (Basso, 1999), enquanto, em 1998, foram de 4,45, 4,18 e 3,79 $\mathrm{Mg} \mathrm{ha}^{-1}$. É importanteressaltar que, no primeiro ano, as plantas de cobertura de solo no inverno foram semeadas sobre restos culturais de soja que havia sido cultivada no verão antes da instalação do experimento.

Os teores de $\mathrm{N}$ mineral no sol o nos manejos com 00-00-00 e 00-30-90 são repetições em todos os sistemas de cultura, na avaliação realizada imediatamente antes da semeadura, porque, até então, em nenhum dos casos havia sido aplicado N, o que faz com que os valores sejam semel hantes.

No sistema aveia preta/milho, quando da avaliação feita imediatamente antes da semeadura do milho, observou-se que o aumento na quantidade de $\mathrm{N}$ aplicado em pré-semeadura resultou em incremento nos teores de $\mathrm{N}$ mineral do solo, principalmente nas camadas de $0-5$ e $5-10 \mathrm{~cm}$ de profundidade (Quadro 1). Por outro Iado, na avaliação realizada no período de florescimento do milho, os teores de $\mathrm{N}$ mineral do solo foram mais uniformes em quase todas as profundidades desolo. Esse comportamento diferenciado nas duas épocas de amostragem do sol o pode estar relacionado com a imobilização de $\mathrm{N}$, mas também evidencia a alta mobilidade do $\mathrm{N}$ mineral. Basta verificar que, neste intervalo de tempo, o manejo com $90 \mathrm{~kg} \mathrm{ha}^{-1}$ de N aplicado em pré-semeadura do mil ho sofreu o efeito de precipitações pluviais acumuladas de $502 \mathrm{~mm}$, contra $130 \mathrm{~mm}$ no sistema onde os $90 \mathrm{~kg} \mathrm{ha}^{-1}$ de N foram aplicados em cobertura (Figura 1). Outra evidência da mobilidade do $\mathrm{N}$ mineral no solo é mostrada no sistema onde foi aplicado $90 \mathrm{~kg} \mathrm{ha}^{-1} \mathrm{em}$ pré-semeadura do milho, porque da primeira para a última avaliação os teores de $\mathrm{N}$ mineral foram aumentando em profundidade.

No sistema aveia preta + ervilhaca/milho, os efeitos foram semelhantes aos supradescritos no sistema aveia preta/milho (Quadro 2). Entretanto, na comparação dos sistemas de cultura, no manejo do $\mathrm{N}$ com 00-30-90, que corresponde à forma tradicional defracionamento na aplicação de $\mathrm{N}$ para o milho, observou-se que com a introdução da ervilhaca como leguminosa, consorciada coma aveia 
Quadro 1. Teor de nitrogênio mineral $\left(\mathrm{NO}_{3}{ }^{-}+\mathrm{NH}_{4}{ }^{+}\right)$, em diferentes períodos e profundidades de solo, antes e durante o desenvolvimento do milho, em sucessão à aveia preta no ano agrícola 1996/97

\begin{tabular}{|c|c|c|c|c|c|}
\hline \multirow{2}{*}{ Profundidade $^{(1)}$} & \multicolumn{5}{|c|}{ Manejo de N para o milho(2) $(k$ ha-1) } \\
\hline & $00-00-00$ & $00-30-90$ & $30-30-60$ & $60-30-30$ & $90-30-00$ \\
\hline \multirow[t]{2}{*}{$\mathrm{cm}$} & & 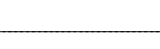 & $g^{-1}$ de $N$ nos & 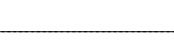 & - \\
\hline & \multicolumn{5}{|c|}{ I mediatamente antes da semeadura do milho } \\
\hline $\begin{array}{c}0-5 \\
5-10 \\
10-20 \\
20-40\end{array}$ & $\begin{array}{c}29,6 \mathrm{aC}(3) \\
12,1 \mathrm{bB} \\
4,1 \mathrm{cC} \\
3,2 \mathrm{cB}\end{array}$ & $\begin{array}{r}29,6 \mathrm{aC} \\
11,9 \mathrm{bB} \\
4,5 \mathrm{cC} \\
3,1 \mathrm{cB}\end{array}$ & $\begin{array}{r}46,5 \mathrm{aB} \\
10,7 \mathrm{bB} \\
9,1 \mathrm{bA} \\
2,3 \mathrm{cB}\end{array}$ & $\begin{array}{c}71,1 \mathrm{aA} \\
12,3 \mathrm{bB} \\
7,4 \mathrm{bAB} \\
9,1 \mathrm{bA}\end{array}$ & $\begin{array}{r}83,7 \mathrm{aA} \\
23,0 \mathrm{bA} \\
5,6 \mathrm{cB} \\
4,6 \mathrm{cB}\end{array}$ \\
\hline \multirow[t]{2}{*}{ Média(4) } & 7,8 & 7,9 & 10,6 & 16,8 & 17,0 \\
\hline & \multicolumn{5}{|c|}{ Imediatamente antes da aplicação do $\mathbf{N}$ em cobertura } \\
\hline $\begin{array}{c}0-5 \\
5-10 \\
10-20 \\
20-40\end{array}$ & $\begin{array}{l}9,7 \mathrm{aA} \\
7,6 \mathrm{abA} \\
6,8 \mathrm{abA} \\
6,5 \mathrm{bB}\end{array}$ & $\begin{array}{r}11,3 \mathrm{aA} \\
6,7 \mathrm{bA} \\
7,6 \mathrm{bA} \\
7,2 \mathrm{bB}\end{array}$ & $\begin{array}{r}11,6 \mathrm{aA} \\
9,6 \mathrm{aA} \\
6,1 \mathrm{bA} \\
6,6 \mathrm{bB}\end{array}$ & $\begin{array}{r}11,3 \mathrm{aA} \\
9,1 \mathrm{aA} \\
9,6 \mathrm{aA} \\
12,3 \mathrm{aA}\end{array}$ & $\begin{array}{r}10,2 \mathrm{aA} \\
5,9 \mathrm{aA} \\
9,9 \mathrm{aA} \\
10,3 \mathrm{aA}\end{array}$ \\
\hline \multirow[t]{2}{*}{ Média } & 7,1 & 7,8 & 7,5 & 11,1 & 9,6 \\
\hline & \multicolumn{5}{|c|}{ No período do florescimento do milho } \\
\hline $\begin{array}{c}0-5 \\
5-10 \\
10-20 \\
20-40\end{array}$ & $\begin{array}{l}2,9 \mathrm{aB} \\
0,9 \mathrm{bB} \\
1,1 \mathrm{bB} \\
0,8 \mathrm{bC}\end{array}$ & $\begin{array}{l}3,0 \mathrm{bB} \\
5,2 \mathrm{abA} \\
5,1 \mathrm{abA} \\
8,9 \mathrm{aA}\end{array}$ & $\begin{array}{l}2,7 \mathrm{abB} \\
2,7 \mathrm{abAB} \\
1,8 \mathrm{bB} \\
3,7 \mathrm{aBC}\end{array}$ & $\begin{array}{l}6,2 \mathrm{aA} \\
3,3 \mathrm{abAB} \\
2,1 \mathrm{bB} \\
5,0 \mathrm{abB}\end{array}$ & $\begin{array}{l}3,8 \mathrm{bB} \\
1,0 \mathrm{cB} \\
1,2 \mathrm{cB} \\
4,8 \mathrm{aB}\end{array}$ \\
\hline Média & 1,2 & 6,8 & 3,0 & 4,2 & 3,3 \\
\hline
\end{tabular}

(1) Profundidade de amostragem de solo. ${ }^{(2)} 00-00-00$ = significa a aplicação de $\mathrm{N}$ no mil ho $\left(\mathrm{kg} \mathrm{ha}^{-1}\right)$ em pré-semeadura, semeadura e cobertura, respectivamente. (3) Médias com mesma letra maiúscula, na linha, e minúscula, na coluna, não diferem pelo teste de Duncan a 5\%. Coeficiente de variação médio de 31,5 e 34,9\%, para linhas e colunas, respectivamente.

(4) Média ponderada $=\frac{(\text { teor } 0-5 \times 5)+(\text { teor } 5-10 \times 5)+(\text { teor } 10-20 \times 10)+(\text { teor } 20-40 \times 20)}{40}$

Teores de $\mathrm{N}$ mineral no manejo da aveia preta: 6,0, 3,7, 4,5 e 2,8 $\mathrm{mg} \mathrm{kg}^{-1}$ de $\mathrm{N}$ no solo, nas profundidades de 0-5, 5-10, 10-20 e 20$40 \mathrm{~cm}$, respectivamente.

Ano agrícola 1996/97

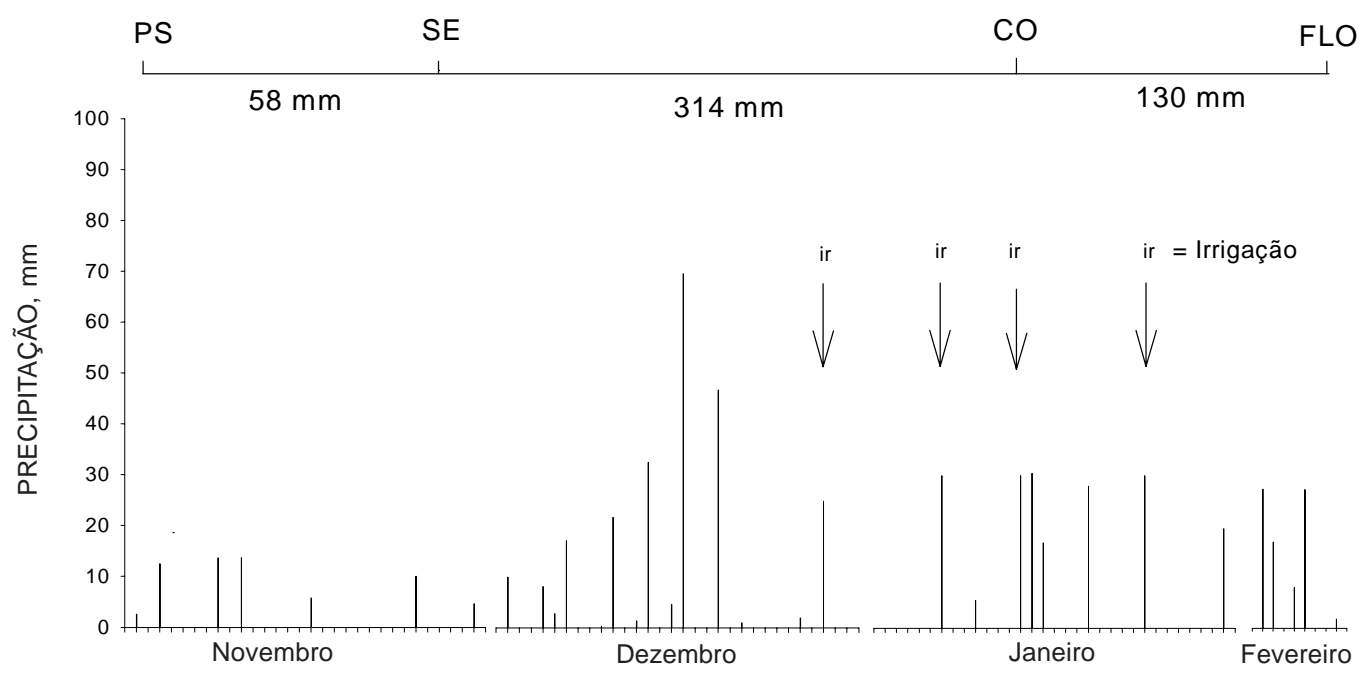

Figura 1. Distribuição das chuvas no período da aplicação do $\mathrm{N}$ em pré-semeadura (PS) até o floresci mento (FLO) do milho no primeiro ano agrícola. 
preta, não houve diferença nos teores de $\mathrm{N}$ mineral em profundidade do solo na avaliação feita imediatamente antes da aplicação do $\mathrm{N}$ em cobertura. I sso sugere que a quantidade de $\mathrm{N}$ liberada pel os resíduos de ervilhaca contribuiu para a distribuição do $\mathrm{N}$ mineral em profundidade e que a avaliação até $40 \mathrm{~cm}$ de profundidade não foi suficiente para detectar diferenças na quantidade de $\mathrm{N}$ mineral. A contribuição da ervilhaca no incremento de $\mathrm{N}$ mineral no solo no sistema aveia preta + ervilhaca/milho pode ser também visualizada ao compará-la com o sistema com aveia preta/milho e sem aplicação de N mineral.

No sistema com nabo forrageiro/milho, é interessante verificar que os teores de $\mathrm{N}$ mineral no solo na avaliação feita na camada de $0-5 \mathrm{~cm}$ de profundidade e antes da semeadura do milho atingiram valores médios de $22,8 \mathrm{mg} \mathrm{kg}^{-1}$ de $\mathrm{N}$ no solo, contra 29,6 e 37,7 $\mathrm{mg} \mathrm{kg}^{-1}$ nos sistemas com aveia preta/milho e aveia preta + ervilhaca/milho, respectivamente, nos manejos 00-00-00 e 00-30-90
(Quadro 3). Por outro lado, no sistema com nabo forrageiro, oteor de $\mathrm{N}$ mineral na camada de $5-10 \mathrm{~cm}$ foi de $18,6 \mathrm{mg} \mathrm{kg}^{-1}$ de $\mathrm{N}$ de solo, contra 12,0 e 13,3 nos sistemas com aveia preta/milho e aveia preta + ervilhaca/milho, respectivamente. Por essa razão, ao contrário dos outros sistemas de culturas, quando havia nabo forrageiro, não houve diferença entre os teores de $\mathrm{N}$ mineral no solo nas profundidades de $0-5$ e $5-10 \mathrm{~cm}$. I sso confirma observações em campo onde o nabo forrageiro decompõe-serapidamente, facilitando a redistribuição do $\mathrm{N}$ mineral no solo.

É importante observar que, especialmente nos sistemas aveia preta/milho eaveia preta+ervilhaca/ milho, os teores de $\mathrm{N}$ mineral no solo na avaliação feita no período de florescimento do milho foram maiores no sistema tradicional de manejo do $\mathrm{N}$ à cultura do milho, ou seja, $30 \mathrm{~kg} \mathrm{ha}^{-1}$ na semeadura e $90 \mathrm{~kg} \mathrm{ha}^{-1}$ em cobertura e isso pode ser desejável para a produtividade de grãos. Entretanto, no manejo tradicional de $\mathrm{N}$, embora tenha acumulado

Quadro 2. Teor de nitrogênio mineral $\left(\mathrm{NO}_{3}{ }^{-}+\mathrm{NH}_{4}{ }^{+}\right)$, em diferentes períodos e profundidades de solo, antes e durante o desenvolvimento do mi lho, em sucessão à aveia preta +ervilhaca no ano agrícola 1996/97

\begin{tabular}{|c|c|c|c|c|c|}
\hline \multirow{2}{*}{ Profundidade(1) } & \multicolumn{5}{|c|}{ Manejo de N para o milho(2) (kg ha-1) } \\
\hline & $00-00-00$ & 00-30-90 & $30-30-60$ & 60-30-30 & $90-30-00$ \\
\hline \multirow[t]{2}{*}{$\mathrm{cm}$} & & 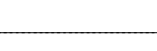 & $g^{-1}$ de N no & - & - \\
\hline & \multicolumn{5}{|c|}{ I mediatamente antes da semeadura do milho } \\
\hline $\begin{array}{c}0-5 \\
5-10 \\
10-20 \\
20-40\end{array}$ & $\begin{array}{c}37,8 \mathrm{aC}^{(3)} \\
13,3 \mathrm{bB} \\
4,9 \mathrm{cB} \\
4,5 \mathrm{cA}\end{array}$ & $\begin{array}{r}37,5 \mathrm{aC} \\
13,3 \mathrm{bB} \\
5,7 \mathrm{cB} \\
4,6 \mathrm{cA}\end{array}$ & $\begin{array}{r}39,9 \mathrm{aC} \\
15,9 \mathrm{bB} \\
4,5 \mathrm{cB} \\
7,4 \mathrm{cA}\end{array}$ & $\begin{array}{c}80,5 \mathrm{aA} \\
26,8 \mathrm{bA} \\
6,4 \mathrm{cAB} \\
6,9 \mathrm{cA}\end{array}$ & $\begin{array}{c}60,7 \mathrm{aB} \\
24,4 \mathrm{bA} \\
8,2 \mathrm{cA} \\
4,3 \mathrm{cA}\end{array}$ \\
\hline \multirow[t]{2}{*}{ Média(4) } & 9,9 & 10,1 & 11,8 & 18,5 & 14,8 \\
\hline & \multicolumn{5}{|c|}{ Imediatamente antes da aplicação do $\mathrm{N}$ em cobertura } \\
\hline $\begin{array}{c}0-5 \\
5-10 \\
10-20 \\
20-40\end{array}$ & $\begin{array}{l}9,8 \mathrm{aA} \\
5,8 \mathrm{bB} \\
5,5 \mathrm{bA} \\
5,3 \mathrm{bB}\end{array}$ & $\begin{array}{r}11,1 \mathrm{aA} \\
3,5 \mathrm{bB} \\
5,6 \mathrm{abA} \\
8,6 \mathrm{abA}\end{array}$ & $\begin{array}{l}9,0 \mathrm{aA} \\
3,3 \mathrm{aB} \\
6,7 \mathrm{aA} \\
8,9 \mathrm{aAB}\end{array}$ & $\begin{array}{r}11,2 \mathrm{aA} \\
10,2 \mathrm{aA} \\
9,6 \mathrm{aA} \\
10,9 \mathrm{aA}\end{array}$ & $\begin{array}{r}6,8 \mathrm{bA} \\
5,5 \mathrm{bB} \\
7,4 \mathrm{bA} \\
11,8 \mathrm{aA}\end{array}$ \\
\hline \multirow[t]{2}{*}{ Média } & 6,0 & 7,5 & 7,7 & 10,5 & 9,3 \\
\hline & \multicolumn{5}{|c|}{ No período do florescimento do milho } \\
\hline $\begin{array}{c}0-5 \\
5-10 \\
10-20 \\
20-40\end{array}$ & $\begin{array}{l}2,4 \mathrm{aAB} \\
3,1 \mathrm{aAB} \\
3,0 \mathrm{aB} \\
3,2 \mathrm{aB}\end{array}$ & $\begin{array}{l}5,5 \mathrm{aA} \\
5,0 \mathrm{aA} \\
4,4 \mathrm{aA} \\
8,0 \mathrm{aA}\end{array}$ & $\begin{array}{l}3,9 \mathrm{aAB} \\
3,5 \mathrm{aAB} \\
3,9 \mathrm{aA} \\
6,7 \mathrm{aA}\end{array}$ & $\begin{array}{l}1,9 \mathrm{bB} \\
2,0 \mathrm{bAB} \\
2,8 \mathrm{bA} \\
8,3 \mathrm{aA}\end{array}$ & $\begin{array}{l}1,8 \mathrm{bB} \\
1,3 \mathrm{bB} \\
1,0 \mathrm{bA} \\
4,4 \mathrm{aB}\end{array}$ \\
\hline Média & 3,0 & 6,4 & 5,3 & 5,3 & 2,8 \\
\hline
\end{tabular}

(1) Profundidade de amostragem de solo. ${ }^{(2)} 00-00-00$ = significa a aplicação de N no milho $\left(\mathrm{kg} \mathrm{ha}^{-1}\right)$ em pré-semeadura, semeadura e cobertura, respectivamente. (3) Médias com mesma letra maiúscula, na linha, e minúscula, na coluna, não diferem pelo teste de Duncan a 5\%. Coeficiente de variação médio de 34,2 e 36,4\%, para linhas e colunas, respectivamente.

(4) Média ponderada $=\frac{(\text { teor } 0-5 \times 5)+(\text { teor } 5-10 \times 5)+(\text { teor } 10-20 \times 10)+(\text { teor } 20-40 \times 20)}{40}$

Teores de $\mathrm{N}$ mineral no manejo da aveia preta +ervilhaca: 7,2 3,9 3,1 e 4,0 $\mathrm{mg} \mathrm{kg}^{-1}$ de $\mathrm{N}$ no solo nas profundidades de 0-5, 5-10, 1020 e $20-40 \mathrm{~cm}$, respectivamente. 
Quadro 3. Teor de nitrogênio mineral $\left(\mathrm{NO}_{3}{ }^{-}+\mathrm{NH}_{4}{ }^{+}\right)$, em diferentes períodos e profundidades de solo, antes e durante o desenvolvimento do milho, em sucessão ao nabo forrageiro no ano agrícola 1996/97

\begin{tabular}{|c|c|c|c|c|c|}
\hline \multirow{2}{*}{ Profundidade ${ }^{(1)}$} & \multicolumn{5}{|c|}{ Manejo de $\mathrm{N}$ para o milho(2) (kg ha-1) } \\
\hline & $00-00-00$ & 00-30-90 & $30-30-60$ & $60-30-30$ & $90-30-00$ \\
\hline \multirow[t]{2}{*}{$\mathrm{cm}$} & & 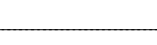 & $\mathrm{g}^{-1}$ de $\mathrm{N}$ no & 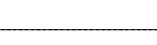 & - \\
\hline & \multicolumn{5}{|c|}{ I mediatamente antes da semeadura do milho } \\
\hline $\begin{array}{c}0-5 \\
5-10 \\
10-20 \\
20-40\end{array}$ & $\begin{array}{c}22,9 \mathrm{aC}(3) \\
18,5 \mathrm{aA} \\
6,1 \mathrm{bA} \\
3,5 \mathrm{bB}\end{array}$ & $\begin{array}{r}22,7 \mathrm{aC} \\
18,7 \mathrm{aA} \\
6,2 \mathrm{bA} \\
3,4 \mathrm{bB}\end{array}$ & $\begin{array}{c}42,3 \mathrm{aB} \\
10,6 \mathrm{bA} \\
5,3 \mathrm{cA} \\
4,4 \mathrm{cB}\end{array}$ & $\begin{array}{c}49,9 \mathrm{aB} \\
16,1 \mathrm{bA} \\
8,4 \mathrm{cA} \\
5,8 \mathrm{cAB}\end{array}$ & $\begin{array}{r}65,9 \mathrm{aA} \\
17,2 \mathrm{bA} \\
4,6 \mathrm{cA} \\
7,7 \mathrm{cA}\end{array}$ \\
\hline \multirow[t]{2}{*}{ Média(4) } & 8,5 & 8,4 & 10,1 & 13,2 & 15,4 \\
\hline & \multicolumn{5}{|c|}{ I mediatamente antes da aplicação do $\mathbf{N}$ em cobertura } \\
\hline $\begin{array}{c}0-5 \\
5-10 \\
10-20 \\
20-40\end{array}$ & $\begin{array}{c}10,3 \mathrm{aA} \\
5,3 \mathrm{cB} \\
7,2 \mathrm{bB} \\
7,2 \mathrm{bBC}\end{array}$ & $\begin{array}{c}11,8 \mathrm{aA} \\
8,6 \mathrm{bAB} \\
6,1 \mathrm{bB} \\
3,5 \mathrm{bC}\end{array}$ & $\begin{array}{r}11,6 \mathrm{aA} \\
7,7 \mathrm{bB} \\
7,6 \mathrm{bB} \\
9,2 \mathrm{aB}\end{array}$ & $\begin{array}{l}16,9 \mathrm{aA} \\
12,0 \mathrm{aA} \\
13,9 \mathrm{aA} \\
13,4 \mathrm{aA}\end{array}$ & $\begin{array}{r}11,7 \mathrm{aA} \\
5,7 \mathrm{bB} \\
9,4 \mathrm{aB} \\
13,5 \mathrm{aA}\end{array}$ \\
\hline \multirow[t]{2}{*}{ Média } & 7,4 & 5,8 & 8,9 & 13,8 & 11,3 \\
\hline & \multicolumn{5}{|c|}{ No período do florescimento do milho } \\
\hline $\begin{array}{c}0-5 \\
5-10 \\
10-20 \\
20-40\end{array}$ & $\begin{array}{l}2,2 \mathrm{aA} \\
2,8 \mathrm{aA} \\
2,9 \mathrm{aBC} \\
3,0 \mathrm{aB}\end{array}$ & $\begin{array}{l}3,4 \mathrm{aA} \\
3,7 \mathrm{aA} \\
6,4 \mathrm{aA} \\
4,4 \mathrm{aB}\end{array}$ & $\begin{array}{l}3,2 \mathrm{bA} \\
3,3 \mathrm{bA} \\
4,2 \mathrm{bB} \\
6,7 \mathrm{aA}\end{array}$ & $\begin{array}{l}3,2 \mathrm{abA} \\
4,7 \mathrm{aA} \\
2,0 \mathrm{bBC} \\
3,6 \mathrm{abB}\end{array}$ & $\begin{array}{l}2,9 \mathrm{cA} \\
4,0 \mathrm{bA} \\
1,4 \mathrm{dC} \\
6,8 \mathrm{aA}\end{array}$ \\
\hline Média & 2,9 & 4,7 & 5,2 & 3,3 & 4,6 \\
\hline
\end{tabular}

(1) Profundidade de amostragem de solo. ${ }^{(2)}$ 00-00-00 = significa a aplicação de N no milho (kg ha-1) em pré-semeadura, semeadura e cobertura, respectivamente. (3) Médias com mesma letra maiúscula, na linha, e minúscula, na coluna, não diferem pelo teste de Duncan a 5\%. Coeficiente de variação médio de 37,7 e 33,7\%, para linhas e colunas, respectivamente.

(4) Média ponderada $=\frac{(\text { teor } 0-5 \times 5)+(\text { teor } 5-10 \times 5)+(\text { teor } 10-20 \times 10)+(\text { teor } 20-40 \times 20)}{40}$

Teores de $\mathrm{N}$ mineral no manejo do nabo forrageiro: 6,8 3,8 4,4 e 4,7 mg kg ${ }^{-1}$ de $\mathrm{N}$ no solo nas profundidades de 0-5, 5-10, 10-20 e 20$40 \mathrm{~cm}$, respectivamente.

mais $\mathrm{N}$ mineral no solo no período de florescimento do milho, isso não se refletiu na quantidade de $\mathrm{N}$ absorvido pelas plantas de milho e sua produtividade, conforme é discutido nos itens seguintes.

$\mathrm{Na}$ maioria dos sistemas de manejo de $\mathrm{N}$, não houve influência das plantas de cobertura de solo sobre o teor de $\mathrm{N}$ mineral e isso em parte pode ser devido à contribuição de $\mathrm{N}$ do resíduo de soja que foi cultivada antes das plantas de cobertura (Quadro 4).

No segundo ano agrícola (97/98), ocorreu o fenômeno EI Niño, que se caracteriza pelo excesso de precipitações pluviais, o que pode ser comprovado pelas figuras 1 e 2, onde são mostradas as chuvas ocorridas nos dois primeiros anos. No período entre a aplicação do $\mathrm{N}$ em pré-semeadura atéà semeadura do milho, houve $58 \mathrm{~mm}$ de precipitação pluvial em 1996/97, contra 243 mm em 1997/98. Essas condições ambientais diferenciadas tiveram reflexos diretos sobre os teores de $\mathrm{N}$ mineral no solo, avaliados imediatamente antes da semeadura do milho, dada a alta mobilidade do N (Figura 3), razão pela qual os teores de $\mathrm{N}$ mineral do solo foram inferiores e semel hantes em todas as profundidades analisadas em 1997/98, ao contrário do observado no ano agrícola anterior, quando houve acumulação de N mineral nas camadas de $0-5$ e $5-10 \mathrm{~cm}$.

Alguns pesquisadores têm encontrado, sob condições normais de clima, perdas pouco expressivas de N por lixiviação (Libardi \& Reichardt, 1987; Coel ho, 1987). Para Camargo et al. (1989), as perdas de $\mathrm{N}$ por lixiviação só foram observadas em sol os com $790 \mathrm{~g} \mathrm{~kg}^{-1}$ de areia e sob uma preci pitação de $200 \mathrm{~mm}$ em duas semanas. Aliás, tais condições assemel ham-se ao solo com $760 \mathrm{~g} \mathrm{~kg}^{-1}$ de areia e os $243 \mathrm{~mm}$ de chuva da pré-semeadura até à semeadura do milho ocorrida no segundo ano deste trabalho.

\section{Acúmulo de nitrogênio na parte aérea do milho}

A ocorrência do fenômenoEI Niño no ano agrícola 1997/98 e seus reflexos nos teores de N mineral do 
Ano Agricola 1997/98

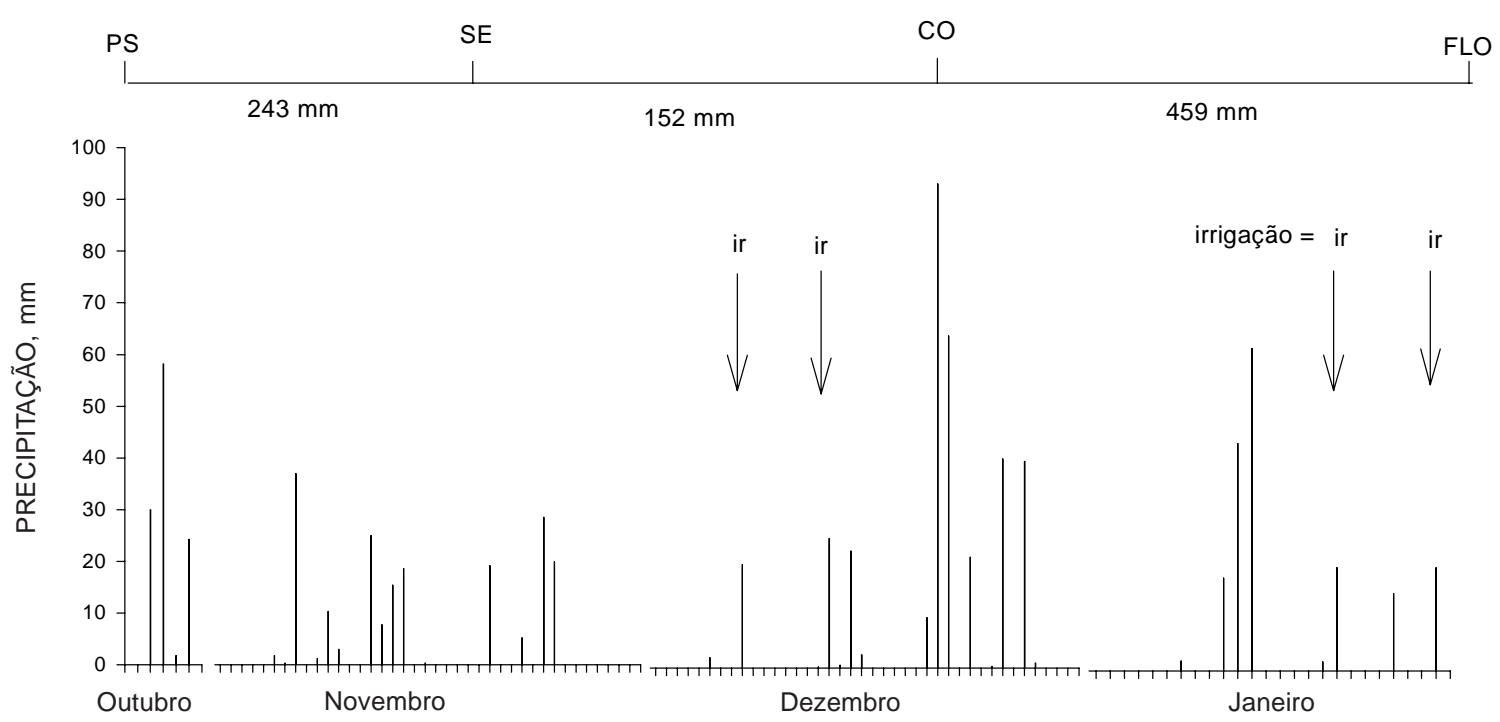

Figura 2. Distribui ção das chuvas no período da aplicação do $\mathbf{N}$ em pré-semeadura (PS) até o florescimento (FLO) do milho no segundo ano agrícola.

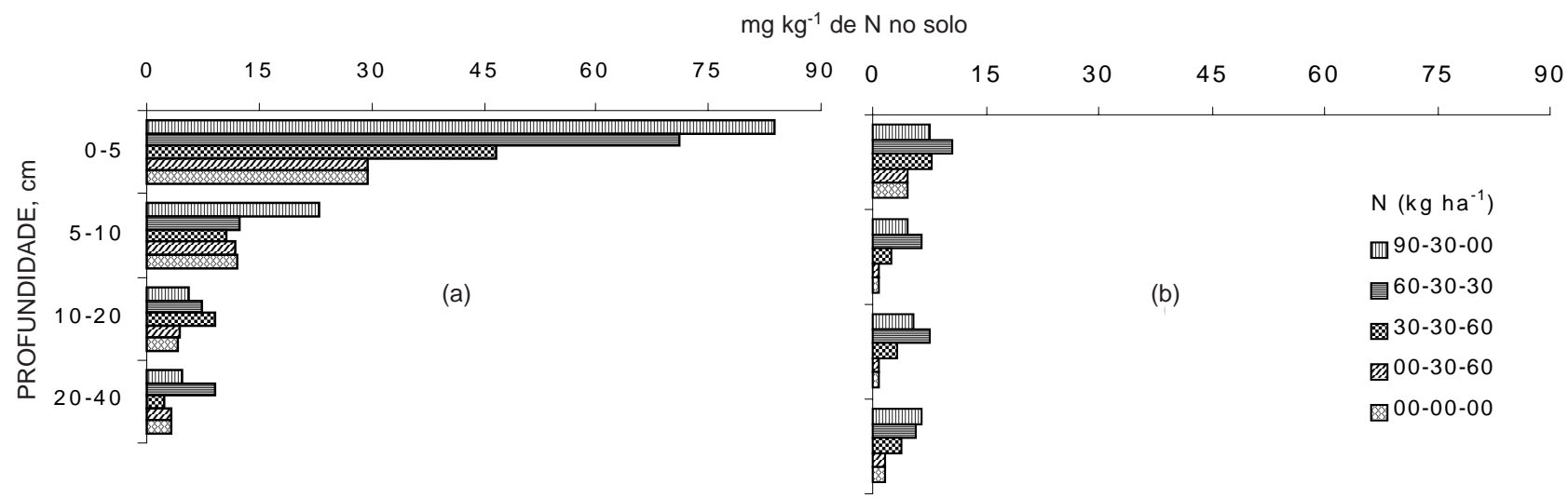

Figura 3. Teores de $\mathbf{N}$ mineral do solo avaliado imediatamente antes da semeadura do milho em sucessão à aveia preta, nos dois anos agrícolas, 1996/97 (a) e 1997/98 (b).

solo são mostrados na figura 3 e isso justifica as menores quantidades de $\mathrm{N}$ absorvido pelas plantas de milho em 1997/98, independentemente das plantas de cobertura que antecederam ao milho (Quadro 5).

$\mathrm{Na}$ ausência da adubação nitrogenada, a quantidade de $\mathrm{N}$ absorvido pelo milho foi favorecida quando cultivado em sucessão à aveia preta + ervilhaca, em relação ao sistema com aveia preta antes do milho. Em termos gerais, observou-se que, nos três anos, houve tendência de maior absorção de $\mathrm{N}$ pelo milho, quando cultivado após aveia preta +ervilhaca. A contribuição da ervilhaca e do nabo forrageiro para absorção de $\mathrm{N}$ pel o milho pode ser notada no primeiro ano, quando a quantidade de $\mathrm{N}$ absorvido pelas plantas de milho não foi influenciada pela aplicação de $\mathrm{N}$ mineral, diferentemente dos anos subseqüentes. I sso deve-se provavelmente ao efeito cumulativo da contribuição dos resíduos de ervilhaca e nabo forrageiro, além dos resíduos da soja cultivada antes da instalação das plantas de cobertura de solo no primeiro ano do experimento. J á no segundo e no terceiro ano agrícola, o efeito sobre a absorção de $\mathrm{N}$ pelo milho foi mais influenciado pelos resíduos de ervilhaca e nabo forrageiro, cultivados anteriormenteao milho, porque estas plantas de cobertura foram cultivadas sobre resíduos de milho.

No sistema aveia preta/milho, nos anos agrícolas de 1996/97 e 1998/99, quando não ocorreu excesso 
Quadro 4. Média ponderada $(0-40 \mathrm{~cm})$ do teor de nitrogênio mineral $\left(\mathrm{NO}_{3}{ }^{-}+\mathrm{NH}_{4}{ }^{+}\right)$em solo com diferentes plantas de cobertura e manejos de nitrogênio, antes e durante o desenvolvimento do milho no ano agrícola 1996/97

\begin{tabular}{|c|c|c|c|}
\hline \multirow{2}{*}{ Aplicação de $\mathbf{N}^{(1)}$} & \multicolumn{3}{|c|}{ Planta de cobertura de solo no inverno } \\
\hline & Aveia preta & Aveia + ervilhaca & Nabo forrageiro \\
\hline $\mathrm{kg} \mathrm{ha}^{-1}$ & 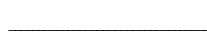 & $-\mathrm{mg} \mathrm{kg}^{-1}$ de $\mathrm{N}$ no solc & - \\
\hline PS SE CO & \multicolumn{3}{|c|}{ Imediatamente antes da semeadura do milho } \\
\hline $\begin{array}{l}00-00-00 \\
00-30-90 \\
30-30-60 \\
60-30-30 \\
90-30-00\end{array}$ & $\begin{array}{l}7,85 \mathrm{cA}^{(2)} \\
7,88 \mathrm{cA} \\
10,54 \mathrm{bA} \\
16,82 \mathrm{aAB} \\
17,05 \mathrm{aA}\end{array}$ & $\begin{array}{c}9,89 \mathrm{cA} \\
10,01 \mathrm{cA} \\
11,81 \mathrm{bcA} \\
18,29 \mathrm{aA} \\
14,82 \mathrm{abA}\end{array}$ & $\begin{array}{r}8,41 \mathrm{bA} \\
8,42 \mathrm{bA} \\
10,14 \mathrm{bA} \\
13,22 \mathrm{aB} \\
15,39 \mathrm{aA}\end{array}$ \\
\hline $90-30-00$ & \multicolumn{3}{|c|}{ Imediatamente antes da aplicação do $\mathrm{N}$ em cobertura } \\
\hline $\begin{array}{l}00-00-00 \\
00-30-90 \\
30-30-60 \\
60-30-30 \\
90-30-00\end{array}$ & $\begin{array}{c}7,10 \mathrm{cA} \\
7,76 \mathrm{bcA} \\
7,51 \mathrm{cA} \\
11,08 \mathrm{aAB} \\
9,6 \mathrm{abA}\end{array}$ & $\begin{array}{c}5,96 \mathrm{bA} \\
7,51 \mathrm{abA} \\
7,68 \mathrm{abA} \\
10,55 \mathrm{aB} \\
9,31 \mathrm{abA}\end{array}$ & $\begin{array}{r}7,35 \mathrm{cA} \\
7,53 \mathrm{cA} \\
8,89 \mathrm{cA} \\
13,80 \mathrm{aA} \\
11,25 \mathrm{bA}\end{array}$ \\
\hline $90-30-00$ & \multicolumn{3}{|c|}{ No período de florescimento do milho } \\
\hline $\begin{array}{l}00-00-00 \\
00-30-90 \\
30-30-60 \\
60-30-30 \\
90-30-00\end{array}$ & $\begin{array}{l}1,15 \mathrm{cA} \\
6,73 \mathrm{aA} \\
2,97 \mathrm{bcB} \\
4,22 \mathrm{bA} \\
3,15 \mathrm{bcB}\end{array}$ & $\begin{array}{l}3,02 \mathrm{bA} \\
6,43 \mathrm{aA} \\
5,26 \mathrm{abA} \\
5,35 \mathrm{abA} \\
2,84 \mathrm{bB}\end{array}$ & $\begin{array}{l}2,84 \mathrm{cA} \\
4,67 \mathrm{abA} \\
5,23 \mathrm{aA} \\
3,28 \mathrm{bcA} \\
4,62 \mathrm{abA}\end{array}$ \\
\hline
\end{tabular}

(1) PS, SE e CO correspondem às épocas de aplicações de nitrogênio para o milho, aplicado em pré-semeadura (27 dias antes da semeadura), semeadura e cobertura (4 a 6 fol has desenroladas), respectivamente. ${ }^{(2)}$ Médias seguidas da mesma letra maiúscula, na linha, e minúscula, na coluna, não diferem pelo teste de Duncan a $5 \%$.

Quadro 5. Quantidade de nitrogênio absorvido pelo mi lho em sucessão a plantas de cobertura de solo no inverno com diferentes manejos da adubação nitrogenada

\begin{tabular}{|c|c|c|c|}
\hline \multirow{2}{*}{ Aplicação de $N^{(1)}$} & \multicolumn{3}{|c|}{ Planta de cobertura de solo no inverno } \\
\hline & Aveia preta & Aveia preta + ervilhaca & $\mathrm{N}$ abo forrageiro \\
\hline $\mathrm{kg} \mathrm{ha}^{-1}$ & 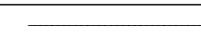 & $\mathrm{kg} \mathrm{ha}^{-1}$ & + \\
\hline PS SE CO & & Ano agrícola 1996/97 & \\
\hline $\begin{array}{l}00-00-00 \\
00-30-90 \\
30-30-60 \\
60-30-30 \\
90-30-00\end{array}$ & $\begin{array}{l}56,23 \text { c B (2) } \\
82,76 \text { bcA } \\
107,14 \text { abA } \\
116,14 \text { aA } \\
77,89 \text { cA }\end{array}$ & $\begin{array}{l}73,76 \text { aA } \\
87,53 \text { aA } \\
91,86 \text { aA } \mathrm{B} \\
93,37 \text { aA } \\
87,68 \text { aA }\end{array}$ & $\begin{array}{l}64,22 \text { aA } B \\
89,73 \text { aA } \\
78,21 \text { a } \\
92,68 \text { aA } \\
94,88 \text { aA }\end{array}$ \\
\hline $90-30-00$ & & Ano agrícola $1997 / 98^{(3)}$ & \\
\hline $\begin{array}{l}00-00-00 \\
00-30-90 \\
30-30-60 \\
60-30-30 \\
90-30-00\end{array}$ & $\begin{array}{l}20,40 \text { cA } \\
63,53 \text { aA } \\
57,72 \text { aA } \\
35,78 \text { bB } \\
26,76 \text { bcA }\end{array}$ & $\begin{array}{l}31,00 \mathrm{cA} \\
67,58 \mathrm{aA} \\
66,81 \mathrm{aA} \\
49,45 \mathrm{bA} \\
26,89 \mathrm{cA}\end{array}$ & $\begin{array}{l}18,12 \text { bA } \\
56,19 \text { aA } \\
59,65 \text { aA } \\
51,32 \text { aA } \\
24,60 \text { bA }\end{array}$ \\
\hline $\begin{array}{l}60-30-30 \\
90-30-00\end{array}$ & & Ano agrícola 1998/99 & \\
\hline $\begin{array}{l}00-00-00 \\
00-30-90 \\
30-30-60 \\
60-30-30 \\
90-30-00\end{array}$ & $\begin{array}{l}37,09 \mathrm{cA} \\
73,62 \mathrm{bA} \\
86,40 \mathrm{abA} \\
80,07 \text { abA } \\
97,92 \text { aA }\end{array}$ & $\begin{array}{c}44,81 \mathrm{bA} \\
82,17 \mathrm{abA} \\
107,05 \mathrm{aA} \\
109,82 \mathrm{aA} \\
104,59 \mathrm{aA}\end{array}$ & $\begin{array}{l}36,87 \text { bA } \\
69,58 \text { a } \\
90,16 \text { a } \\
73,36 \text { a } \\
70,84 \text { a B }\end{array}$ \\
\hline
\end{tabular}

(1) PS, SE e CO correspondem às aplicações de nitrogênio feitas em pré-semeadura (27, 23 e 17 dias antes da semeadura para 0 primeiro, segundo e terceiro ano, respectivamente), semeadura e cobertura (4 a 6 fol has desenroladas do milho) do milho, respectivamente. (2) Médias seguidas da mesma letra maiúscula, na linha, e minúscula, na coluna, não diferem pelo teste de Duncan a $5 \%$. Os coeficiente de variação para aveia preta, aveia preta +ervilhaca e nabo forrageiro foram de 15,6, 15,7, 21,7, 16,7, 11,7 e 20,1 e $15,4,14,4$ e 19,6\%, para o primeiro, segundo e terceiro ano agrícola, respectivamente. ${ }^{(3)}$ Preci pitação el evada nos meses de outubro e novembro de 1997. 
de precipitação pluvial, a aplicação de $\mathrm{N}$ em présemeadura do milho favoreceu a absorção de $\mathrm{N}$ e isso pode estar associado à diminuição do efeito da imobilização microbiana de $\mathrm{N}$, especialmente no início do desenvol vimento do milho.

\section{Produtividade}

O consórcio da aveia pretatervilhaca destacouse como plantas de cobertura de sol o, antecedendo ao cultivo do milho, pois, na ausência da adubação nitrogenada, a produtividade degrãos demilhofoi superior nos anos agrícol as de 1997/98 e 1998/99 (Quadro 6).

Na maioria dos sistemas deculturas, a aplicação de $\mathrm{N}$ favoreceu a produtividade de grãos de milho. Entretanto, o excesso de precipitação pluvial, decorrente do fenômeno EI Niño em 1997/98, limitou a produtividade de grãos de milho, como conseqüência da redução na quantidade de N mineral no sol o e menor quantidade de $\mathrm{N}$ absorvido pelas plantas, conforme discutidoanteriormente. Em função disso, neste ano, a aplicação de $\mathrm{N}$ na forma tradicional, ou seja, na semeadura e o restante em cobertura resultaram em maior produtividade que os manejos com aplicação de $\mathrm{N}$ em pré-semeadura do milho. Neste mesmo ano agrícola, Diekow et al. (1998) realizaram um trabalho em Latossolo Roxo distrófico com teor de argila de $700 \mathrm{~g} \mathrm{~kg}^{-1}$, em Santo Ângelo(RS), há dez anos com plantio direto, quando ficou demonstrado que também em solo argiloso o excesso de chuva tornou inviável a aplicação de N em pré-semeadura do mil ho cultivado em sucessão à aveia preta equea aplicação de $\mathrm{N}$ na semeadura e em cobertura proporcionou maior produtividade de grãos. Entretanto, quando Sá (1996) trabalhou em solo argi loso, a aplicação de $\mathrm{N}$ em pré-semeadura do milho foi vantajosa, mesmo com a ocorrência de $330 \mathrm{~mm}$ de precipitação pluvial da aplicação do N em pré-semeadura até à semeadura do milho.

Nos anos agrícol as 1996/97 e 1998/99, não houve diferença entre os manejos do $\mathrm{N}$ para o milho. A aplicação em pré-semeadura do N para o milho cultivado em sucessão à aveia preta em 1996/97 promoveu acréscimo na produtividade de grãos. Analisando os resultados variáveis, conforme as condições de cada ano e especialmente a ocor rência de preci pitações pluviais, Ceretta (1998) ressalta que no sistema aveia preta/milho a aplicação de $\mathrm{N}$ em pré-semeadura do milho é viável, cujas vantagens poderão ser comprometidas em anos com intensas precipitações pluviais no período de cultivo do mil ho. Por isso, a aplicação de $\mathrm{N}$ em pré-semeadura do milho, embora possa proporcionar acréscimos na produtividade, deve ser encarada com cautela.

Quadro 6. Produtividade de grãos de mi lho em sucessão a plantas para cobertura de solo no inverno com diferentes manejos da adubação nitrogenada

\begin{tabular}{|c|c|c|c|}
\hline \multirow{2}{*}{ Aplicação de $\mathbf{N}^{(1)}$} & \multicolumn{3}{|c|}{ Planta de cobertura de solo no inverno } \\
\hline & Aveia preta & Aveia preta + ervilhaca & Nabo forrageiro \\
\hline $\mathrm{kg} \mathrm{ha}^{-1}$ & 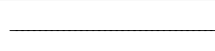 & $\mathrm{kg} \mathrm{ha}^{-1}$ & - \\
\hline PS SE CO & & Ano agrícola 1996/97 & \\
\hline $\begin{array}{l}00-00-00 \\
00-30-90 \\
30-30-60 \\
60-30-30 \\
90-30-00\end{array}$ & $\begin{array}{l}5.616 \mathrm{cA}^{(2)} \\
6.804 \mathrm{bA} \\
6.867 \mathrm{bA} \\
7.756 \mathrm{aA} \\
7.230 \mathrm{abA}\end{array}$ & $\begin{array}{l}6.639 \mathrm{aA} \\
7.122 \mathrm{aA} \\
6.786 \mathrm{aA} \\
7.450 \mathrm{aA} \\
7.567 \mathrm{aA}\end{array}$ & $\begin{array}{l}6.017 \mathrm{bA} \\
6.984 \mathrm{abA} \\
6.767 \mathrm{abA} \\
7.229 \mathrm{aA} \\
6.853 \mathrm{abA}\end{array}$ \\
\hline $90-30-00$ & \multicolumn{3}{|c|}{ Ano agrícola $1997 / 98^{(3)}$} \\
\hline $\begin{array}{l}00-00-00 \\
00-30-90 \\
30-30-60 \\
60-30-30 \\
90-30-00\end{array}$ & $\begin{array}{l}2.812 \mathrm{eB} \\
5.786 \mathrm{aA} \\
5.174 \mathrm{bA} \\
4.322 \mathrm{cA} \\
3.647 \mathrm{dA}\end{array}$ & $\begin{array}{l}4.430 \mathrm{bcA} \\
5.345 \mathrm{abA} \\
5.546 \mathrm{aA} \\
4.971 \mathrm{bA} \\
3.658 \mathrm{cB}\end{array}$ & $\begin{array}{l}2.678 \mathrm{cB} \\
5.542 \mathrm{aA} \\
5.313 \mathrm{abA} \\
4.825 \mathrm{abA} \\
4.496 \mathrm{bA}\end{array}$ \\
\hline & \multicolumn{3}{|c|}{ Ano agrícola 1998/99 } \\
\hline $\begin{array}{l}00-00-00 \\
00-30-90 \\
30-30-60 \\
60-30-30 \\
90-30-00\end{array}$ & $\begin{array}{l}2.522 \mathrm{bB} \\
5.536 \mathrm{aA} \\
5.631 \mathrm{aA} \\
5.527 \mathrm{aA} \\
5.529 \mathrm{aA}\end{array}$ & $\begin{array}{l}4.963 \mathrm{aA} \\
5.075 \mathrm{aA} \\
6.393 \mathrm{aA} \\
5.364 \mathrm{aA} \\
5.933 \mathrm{aA}\end{array}$ & $\begin{array}{l}3.025 \mathrm{bB} \\
4.956 \mathrm{aA} \\
4.996 \mathrm{aA} \\
3.981 \mathrm{abB} \\
5.651 \mathrm{aA}\end{array}$ \\
\hline $\begin{array}{l}\text { (1) PS, SE e CO correspondem } \\
\text { semeadura para o primeiro S } \\
\text { vamente. (2) Médias seguidas } \\
\text { Os coeficientes de variação pa } \\
\text { e } 13,3 \% \text {, para o primeiro, segu }\end{array}$ & $\begin{array}{l}\text { aplicações de nit } \\
\text { arro ano, respecti } \\
\text { ra maiúscula, nã } \\
\text { aveia preta +er } \\
\text { ano, respectivan }\end{array}$ & $\begin{array}{l}\text { ara o milho feitas em pré-sem } \\
\text { e), semeadura e cobertura ( } 4 \text { a } \\
\text { minúscula, na col una, não dif } \\
\text { nabo forrageiro foram de } 4,3 \text {, } \\
\text { Precipitação el evada nos mese }\end{array}$ & $\begin{array}{l}\text { a (27, } 23 \text { e } 17 \text { dias an } \\
\text { as desenroladas), res } \\
\text { pelo teste de Duncan } \\
4 ; 7,1,11,610,4 \text { e } 12,5 \\
\text { tubro e novembro de }\end{array}$ \\
\hline
\end{tabular}




\section{CONCLUSÕES}

1. O milho cultivado em sucessão ao consórcio de aveia pretatervilhaca mostrou mel hor desempenho do que quando cultivado sobre resíduos de aveia preta e nabo forrageiro.

2. Este trabalho, realizado em solo com textura superficial franco-arenosa, mostrou que a aplicação de $\mathrm{N}$ em pré-semeadura do milho é uma atitude de risco, sendo mais segura a aplicação de $\mathrm{N}$ na semeadura e em cobertura no milho.

\section{LITERATURA CITADA}

BARTZ, H.R. Dinâmica dos nutrientes e adubação em sistemas de produção sob plantio direto. In: FRIES, M.R., ed. Plantio direto em solos arenosos: alternativas de manejo para a sustentabilidadeagropecuária. Santa Maria, Departamento de Solos, Universidade F ederal de Santa Maria, 1998. p.5281.

BASSO, C.J . Épocas de aplicação de nitrogênio para milho cultivado em sucessão a plantas de cobertura de solo, no sistema plantio direto. Universidade Federal de Santa Maria, 1999. 91p. (Tese de Mestrado)

BAYER, C. Manejo da fertilidade do sol o na cultura do milho. In: BRESOLIN, M., ed. Contribuição para a cultura do milho para o estado do Rio Grande doSul. Porto Alegre, Fundação de Ciência e Tecnologia-CIENTEC, 1993. p.71-93.

CAMARGO, P.B.; TRIVELIN, P.C.O.; LIBARDI, P.L \& MORAES, S.O.O. Destino do $\mathrm{N}$ defertilizantes $-{ }^{15} \mathrm{~N}$ (uréia aquamônia) aplicada na cultura da cana-de-açúcar. I Deslocamento no solo. In: CONGRESSO BRASILEIRO DE CIÊNCIA DO SOLO, 22., Recife, Resumos. Recife, Sociedade Brasileira Ciência Solo, 1989. p.70-71.

CERETTA, C.A. Adubação nitrogenada no sistema plantio direto: sucessão aveia/milho. In: Conferência anual de plantio direto, 3., Ijuí, 1998. Resumos de palestras. Passo Fundo, Aldeia N orte, 1998. p.49-62.

CERETTA, C.A. \& FRIES, M.R. Adubação nitrogenada no sistema plantio direto. In: NUERNBERG, N.J ., ed. Conceito e fundamentos do sistema plantio direto. Lages, Sociedade de Ciência do Solo-Núcleo Regional Sul, 1998. p.111-120.

COELHO, A.M. Balanço de nitrogênio $\left({ }^{15} \mathrm{~N}\right)$ na cultura do milho (Zea mays L.) em um Latossolo Vermelho-Escuro fase cerrado. Lavras, Escola Superior de Agricultura de Lavras, 1987. 142p. (Tese de Mestrado)
COMISSÃO DE FERTILIDADE DO SOLO - CFSRS/SC. Recomendação de adubação e calagem para o estado do Rio Grande do Sul e Santa Catarina. 3.ed. Passo Fundo, SBCS-Núcleo regional Sul. EMBRAPA/CNPT, 1995. 223p.

DIEKOW, J.; CERETTA, C.A. \& PAVINATO, P. É possível antecipar a adubação nitrogenada no milho no sistema plantio direto? In: REUNIÃO SUL-BRASILEIRA DE CIÊNCIA DO SOLO, 2., Santa Maria, 1998. Resumos expandidos. Santa Maria, Sociedade Brasileira de Ciência do solo, 1998. p.163-166.

EMPRESA BRASILEIRA DE PESQUISA AGROPECUÁRIA EMBRAPA. Centro Nacional de Pesquisa de Solos. Sistema Brasileiro de Classificação de Solos. Brasília, 1999. 412p.

FANCELLI, A.L. \& DOURADO NETO, D. Cultura do milho: aspectos fisiológicos e manejo da água. Inf. Agron., 73:1-4, 1996.

GONÇALVES, C.N. \& CERETTA, C.A. Plantas de cobertura de solo antecedendo o milho e seu efeito sobre o carbono orgânico do solo, sob plantio direto. R. Bras. Ci. Solo, 23:307313, 1999.

LIBARDI, D.L. \& REICHARDT, K. Destino da uréia aplicada a um sol o tropical. R. Bras. Ci. Solo, 2:40-44, 1987.

MATIAS, J.L. Levantamento detalhado de solos da área experimental do Departamento de Solos da UFSM e delimitação da superfície da mudança textural abrupta. Santa Maria, Universidade Federal de Santa Maria, 1996. 91p. (Tese de Mestrado)

RITCHIE, S.W.; HANWAY, J J . \& BENSON. G.O. How a corn Plant Develops. Ames: Iowa State University of Science and Technology, Cooperative Extension Service, 1993. 21p. (Special Report, 48)

SALET, R.L.; VARGAS. L.K.; ANGHINONI, I.; KOCHHANN, R.A $\&$ CONTE, E. Por que a disponibilidade de nitrogênio é menor no sistema plantio direto? In: SEMINÁRIO INTERNACIONAL DO SISTEMA PLANTIO DIRETO, 2., Passo F undo, 1997. Anais. Passo Fundo: 1997. p.217-219.

SÁ, J .C. MORAES. Manejo de nitrogênio na cultura do milho no sistema plantio direto. Passo Fundo, Aldeia Norte, 1996. p.23

TEDESCO, M.J .; GIANELLO, C.; BISSANI, C.A.; BOHNEN, H. \& VOLKWEISS, S.J. Análise de solo, plantas e outros materiais. 2. ed. Porto Alegre, Universidade Federal do Rio Grande do Sul, 1995. 174p. (Bol etim Técnico, 5)

YAMADA, T. Adubação nitrogenada no milho: quanto, como e quando aplicar? Piracicaba, POTAFÓS, 1996. p.15. (Informativo Agronômico, 74) 
C. J . BASSO \& C. A. CERETTA 